\title{
A Major Problem for Patients Over 65 Years of Age: Dizziness
}

\section{Yaş Üstü Hastalarda Major Bir Problem: Dizziness}

\author{
Derya Özdoğru ${ }^{1}$ (D), Mehmet Balal ${ }^{2}$ (D), Şebnem Bıçakçı1 (iD
}

${ }^{1}$ Adana City Training and Research Hospital, Department of Neurology, Adana, Turkey
${ }^{2}$ Cukurova University, Faculty of Medicine, Department of Neurology, Adana, Turkey

\section{ÖZET}

Amaç: Dizziness, uzayda oryantasyon bozukluğu hissini tanımlamak için kullanılan bir terimdir. Halk arasında çok yaygindır ve prevalans1 \%11-32,5 olarak bilinmektedir. Bu oran ileri yaşla birlikte \%60-70'lere kadar çıkmaktadır. Farklı mekanizmalardan kaynaklanan vertigo, dengesizlik, presenkop ve nonspesifik baş dönmesi hissi bu başlığa girer. $\mathrm{Bu}$ çalışmanın amacı 65 yaş ve üzeri dizziness şikayeti ile başvuran hastaların klinik özelliklerini belirlemektir.

Gereç ve Yöntemler: Ocak 2014-Ağustos 2016 tarihleri arasında Çukurova Üniversitesi Tıp Fakültesi Nöroloji Anabilim Dalı polikliniğine dizziness nedeniyle başvuran 65 yaş üstü (52 kadın, 48 erkek) 100 hasta çalışmaya dahil edildi. Hastaların öyküleri, nörolojik ve nörotolojik muayeneleri, laboratuvar değerleri ve ileri tetkik sonuçları kaydedildi.

Bulgular: Hastaların yaş ortalaması 72,6 yıl (minimum: 65, maksimum: 91) olarak belirlendi. Olgular dört gruba ayrıldı. Alt grup analizinde vertigo grubunda 53 (\%51), 21 presenkop (\%20,2), 27 dengesizlik (\%26), 3 nonspesifik sersemlik hissi $(\% 2,8)$ hasta bulunmaktadır. Dört hastada birden fazla neden tespit edildi.

Sonuç: Baş dönmesi, hastaneye başvurmanın en yaygın nedenlerinden biridir ve özellikle geriatrik popülasyonda yaşam kalitesi üzerinde çok olumsuz bir etkiye sahiptir. Doğru teşhis ve tedavi, hastaların yaşam kalitesini arttırır ve merkezi sinir sistemi hastalıklarının erken tanınmasını sağlar.

Anahtar Kelimeler: Dizziness, yaşlı, vertigo, presenkop, dengesizlik

\section{ABSTRACT}

Aim: Dizziness is a term used to describe the sense of disorientation in space. It is prevalent in public, and its prevalence is known to be $11-32.5 \%$. This rate extends to 60 $70 \%$ with advanced age. Vertigo, imbalance, presyncope, and nonspecific sensation of dizziness which originate from different mechanisms, fall within this title. The aim of this study was to determine the clinical characteristics of patients applying with dizziness aged 65 years and over.

Material and Methods: 100 patients over 65 years of age (52 female, 48 male) were admitted to the outpatient clinic of the Neurology Department of Çukurova University Faculty of Medicine between January 2014 and August 2016 due to dizziness included in the study. Mobility difficulty was accepted as an exclusion criterion. Patients' history, neurological and neurotological examinations, laboratory values, and further examination results were recorded.

Results: The patients' mean age was 72.6 years (minimum: 65, maximum: 91). Cases were divided into four groups. In the subgroup analysis, there are 53 patients in the vertigo group (51\%), 21 in presyncope (20.2\%), 27 in imbalance $(26 \%)$, and 3 in nonspecific sensation of dizziness (2.8\%). Multiple causes were identified in four patients.

Conclusion: Dizziness is one of the most common reasons for hospital admission and negatively impacts the quality of life, especially in the geriatric population. Accurate diagnosis and treatment increase patients' quality of life and provide early recognition of central nervous system diseases.

Keywords: Dizziness, older adults, vertigo, presyncope, imbalance

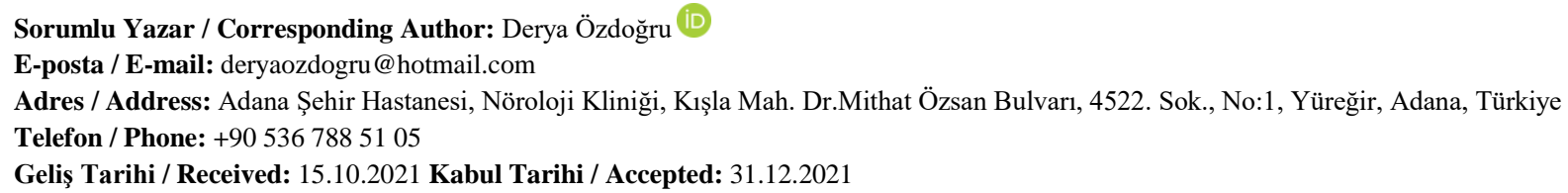




\section{INTRODUCTION}

Dizziness describes the sense of disorientation in space. The patient feels himself/herself in the void, swinging and unstable. The impact of dizziness on the quality of life in older patients is profound (1). Vertigo, imbalance, presyncope, and balance deterioration due to nonspecific causes fall under dizziness (2). Etiological causes vary according to age groups. Treatment is directed accordingly for etiological reasons. The aim of this study was to investigate the etiological causes of dizziness in patients aged 65 years and over.

\section{MATERIAL AND METHODS}

The study included 100 patients over 65 years of age (48 female, 52 male) who were admitted to the outpatient clinic of the Neurology Department of Çukurova University Faculty of Medicine due to balance disorder. An informed consent form was obtained from the people participating in the study. After detailed anamnesis of the patients, neurological and neurotological examinations were performed. In order to determine the etiologic causes, complete blood count, biochemical examinations, cerebral magnetic resonance (MR), carotid-vertebral color doppler ultrasonography (CD-USG), echocardiography (ECHO), and audiometry were planned in all patients. The patients were divided into four groups as vertigo, presyncope, imbalance, and nonspecific causes after history, neurological, neurotological examination, and laboratory evaluations. Patients with severe mobility difficulties (severe polyneuropathy, morbid obesity, severe cognitive impairment, advanced cardiac failure with severe postural instability) were excluded from the study. However, patients with mild cognitive impairment, newly diagnosed polyneuropathy, and Parkinson's disease that did not cause serious mobility problems were included in the study. The study was conducted prospectively with the ethics committee's approval (Cukurova University, 27 - 3.1.2014). This study was carried out according to the principles of the Helsinki Declaration.

\section{Statistical Analysis}

Statistical analysis was performed using IBM SPSS version 20.0 software. Categorical measurements were expressed in numbers and percentages, whereas numerical measurements were expressed as mean and standard deviation. Since the number of patients in vertigo, presyncope, imbalance and nonspecific sensation of dizziness groups was inconsistent, they were not compared among themselves. Independent samples t-test was used to compare numerical measurements between vertigo and non-vertigo, presyncope and non-presyncope, imbalance and nonimbalance. A p-value of $<0.05$ was considered statistically significant in all analyses. SPSS reference: IBM Corp. Released 2011. IBM SPSS Statistics for Windows, Version 20.0. Armonk, NY: IBM Corp.

\section{RESULTS}

The mean age was determined as 72.6 (65-91) years. Demographic data, habits, background, and family history of patients are given in Table I.

Reasons for admission were determined as inclination to falling/fear of falling in 83 (83\%), imbalance in $76 \quad(76 \%)$, the hallucination of motion of surroundings in 43 (43\%), and dizziness in 43 patients (43\%). The main complaint occurs with standing up in 91 (91\%) patients and changing position in 38 (38\%) patients. As accompanying conditions, tinnitus was found in 45 (45\%), hearing loss in $42(42 \%)$, and nausea with varying severity in $53(53 \%)$ patients.

94 patients (94\%) reported acute onset of symptoms and 6 patients $(6 \%)$ reported continuity from the beginning. 33 cases $(33 \%)$ described episodic attacks. The duration of symptoms varied in this group and could not 
Table I. General characteristics of the patients

\begin{tabular}{|c|c|}
\hline Gender (Female/Male) (n) & $48 / 52$ \\
\hline Age (years) & $72,6 \pm 5.9(65-91)$ \\
\hline \multicolumn{2}{|l|}{ Background (n) } \\
\hline Smoking & 13 \\
\hline Alcohol Use & 2 \\
\hline Previous surgery & 66 \\
\hline Hypertension & 70 \\
\hline Diabetes Mellitus & 33 \\
\hline Atherosclerotic heart disease & 43 \\
\hline Thyroid diseases & 7 \\
\hline Cancer history & 5 \\
\hline Psychiatric illness & 5 \\
\hline Chronic Obstructive Pulmonary Disease & 10 \\
\hline Neurological Diseases & 45 \\
\hline Neurodegenerative disease & 14 \\
\hline Previous cerebrovascular event) & 7 \\
\hline Parkinson's disease & 3 \\
\hline Polyneuropathy & 33 \\
\hline Epilepsy & 1 \\
\hline Migraine & 6 \\
\hline Cognitive influences & 14 \\
\hline \multicolumn{2}{|l|}{ Family History (n) } \\
\hline Hypertension & 36 \\
\hline Atherosclerotic heart disease & 20 \\
\hline Diabetes Mellitus & 25 \\
\hline Vertigo & 3 \\
\hline Chronic neurological disease & 14 \\
\hline
\end{tabular}

be obtained clearly, but they were specified as seconds, hours, and days.

Thirty-six patients (36\%) had a history of falling at least once in the last year due to their complaints. Falling was more common, especially in cases with multiple causes. It was determined that a drug was prescribed from the first admission onwards in 51 cases (51\%) to suppress the symptom and piracetam (60\%) and betahistine dihydrochloride $(55 \%)$ were the most commonly used agents.

Patients were divided into four subgroups as vertigo, imbalance, presyncope, and nonspecific sensation. Female gender was found to be statistically significant in the vertigo group ( $\mathrm{p}=0.001)$, and male gender was statistically significant in the presyncope and imbalance groups $(\mathrm{p}=0.003$ and $\mathrm{p}=$ 0.041). In the vertigo group, the complaints of illusion of environment, difficulty in standing ( $p<0.001$ and $p=0.006$ ) and increase in the symptoms with position changes were significant $(\mathrm{p}=0.002)$; in the presyncope subgroup, the presence of blackout and a sense faintness was more frequent $(\mathrm{p}=0.017$ and $\mathrm{p}=0.028$ ) while in the imbalance subgroup, pushing complaints were more frequent than other patients $(\mathrm{p}=0.017)$. In the last group, complaints increased in darkness $(\mathrm{p}<0.001)$.

The presence of cerebellar findings, nystagmus, and speech disorders was significant in patients diagnosed with vertigo compared to other patients $(\mathrm{p}=0.001, \mathrm{p}=$ 0.027, $\mathrm{p}=0.058)$. Dix Hallpike test was positive in 25 patients with vertigo (47.2\%) and was determined to be statistically significant ( $p<0.001) .2$ patients could not comply with the test. Roll test was detected as positive in one patient. The examination results of the patients are shown in Table II.

Table II. Neurotological evaluation

\begin{tabular}{|l|c|}
\hline Evaluation & Abnormal (n) \\
\hline Dysarthria & 5 \\
\hline Head Impulse Test & 3 \\
\hline Skew Deviation & 5 \\
\hline $\begin{array}{l}\text { Eye movements } \\
\text { Slow tracking } \\
\text { Saccades }\end{array}$ & 56 \\
\hline $\begin{array}{l}\text { Gaze-evoked nystagmus } \\
\text { Positional nystagmus }\end{array}$ & 63 \\
\hline $\begin{array}{l}\text { Positional Testing } \\
\text { Dix-Hallpike }\end{array}$ & 18 \\
Roll & 25 \\
\hline $\begin{array}{l}\text { Finger to Nose Test } \\
\text { Knee Heel Test }\end{array}$ & 24 \\
\hline $\begin{array}{l}\text { Posture } \\
\text { Romberg } \\
\text { Tandem }\end{array}$ & 11 \\
\hline
\end{tabular}


Table III. Patients' examinations and results

\begin{tabular}{|c|c|c|}
\hline Examination & Parameter(Abnormal values) & Abnormal (n) \\
\hline \multirow{2}{*}{ Complete Blood Count } & Hemoglobin $(<12 \mathrm{~g} / \mathrm{dl})$ & 13 \\
\hline & Hematocrit (<35\%) & 13 \\
\hline \multirow{4}{*}{ Biochemical } & Fasting Blood Glucose/ HbAlc ( $>110 \mathrm{mg} / \mathrm{dl},>6,5 \%)$ & $28-33$ \\
\hline & $\begin{array}{l}\text { Lipid Profile }(\text { Total cholesterol }>240 \mathrm{mg} / \mathrm{dl}, \mathrm{LDL} \\
\text { cholesterol }>160 \mathrm{mg} / \mathrm{dl} \text {, triglyceride }>500 \mathrm{mg} / \mathrm{dl} \text { ) }\end{array}$ & 12 \\
\hline & Creatinine $(>1.4 \mathrm{mg} / \mathrm{dl})$ & 5 \\
\hline & $\mathrm{B} 12(<180 \mathrm{pg} / \mathrm{ml})$ & 6 \\
\hline \multirow{2}{*}{ Cardiological } & Electrocardiogram (ECG) & 16 \\
\hline & ECHO & 68 \\
\hline \multirow{3}{*}{ Radiological } & $\begin{array}{l}\text { Doppler } \\
\text { Atherosclerosis } \\
\text { Internal carotid artery stenosis }(>\% 50 \text { stenosis }) \\
\text { Vertebral artery stenosis }(>\% 50 \text { stenosis })\end{array}$ & $\begin{array}{r}42 \\
27 \\
12 \\
3\end{array}$ \\
\hline & $\begin{array}{l}\text { Cerebral MRI } \\
\text { Chronic cerebral ischemia } \\
\text { Cerebral atrophy } \\
\text { Cerebellar atrophy } \\
\text { Acute/subacute infarction }\end{array}$ & $\begin{array}{l}86 \\
75 \\
42 \\
33 \\
15\end{array}$ \\
\hline & $\begin{array}{l}\text { Spinal MRI } \\
\text { Lumbar spinal cord compression } \\
\text { Cervical spinal cord compression } \\
\text { Lumbar narrow canal } \\
\text { Nonspecific discopathic changes }\end{array}$ & $\begin{array}{l}12 \\
5 \\
3 \\
2 \\
2\end{array}$ \\
\hline Audiological & Audiometry & 73 \\
\hline
\end{tabular}

Cerebral MRI was performed in all patients participating in the study. Blood and imaging results are shown in Table III. The examination was interpreted as abnormal in 45 patients with vertigo $(84.9 \%)$, in 17 patients with presyncope $(81 \%)$, and in 25 patients with imbalance $(92.6 \%)$. There was no statistically significant difference between the groups $(\mathrm{p}>$ $0.05)$. In patients with vertigo, chronic cerebral ischemia appearance was detected in $37(70 \%)$, cerebral atrophy in 17 (32\%), cerebellar atrophy in $16(30 \%)$, acute-subacute infarct in 15 (28.3\%), schwannoma in one (1.8\%). In patients with presyncope, cerebral ischemia was reported in 15 (71.5\%), cerebral atrophy in $9(43 \%)$, cerebellar atrophy in $6(28.5 \%)$, and in the imbalance group, chronic cerebral ischemia was reported in $24(89 \%)$, cerebral atrophy in 15 (55.5\%), and cerebellar atrophy in $11(41 \%)$.

Spinal MRI examination was planned for 13 patients with characteristics in history and examination findings. It was evaluated as abnormal in 10 patients with imbalance (37\%). Cervical cord compression was detected in 3 of these patients $(11.1 \%)$, narrow lumbar canal in $2(7.5 \%)$, lumbar spinal cord compression in 5 (18.5\%), and cervical discopathic changes were detected in one of the patients with nonspecific sensation of dizziness and one patient with vertigo. Spinal MRI pathology was found to be statistically significant in the imbalance subgroup ( $\mathrm{p}<0.001$ ). 
Table IV. Diagnoses of patients

\begin{tabular}{|c|c|c|c|}
\hline Diagnosis & \multicolumn{2}{|l|}{ Subgroup } & $\mathbf{n}$ \\
\hline \multirow{6}{*}{ Vertigo $\quad(n=53)$} & \multirow[t]{3}{*}{ Central } & $\begin{array}{l}\text { Acute CVE (posterior } \\
\text { circulation ischemia, anterior } \\
\text { circulation ischemia) and }+ \\
\text { vertebral basilar insufficiency }\end{array}$ & $15+3$ \\
\hline & & Vestibular migraine & 4 \\
\hline & & Vestibular schwannoma & 1 \\
\hline & \multirow{2}{*}{ Peripheral } & $\begin{array}{l}\text { Benign paroxysmal positional } \\
\text { vertigo }\end{array}$ & 25 \\
\hline & & Vestibular neuritis & 3 \\
\hline & \multicolumn{2}{|c|}{ Phobic postural vertigo } & 2 \\
\hline \multirow{7}{*}{ Presyncope $(n=21)$} & \multicolumn{2}{|c|}{ Uncontrolled hypertension } & 3 \\
\hline & \multicolumn{2}{|c|}{ Orthostatic hypotension } & 2 \\
\hline & \multicolumn{2}{|c|}{ Drug side effect } & 2 \\
\hline & \multicolumn{2}{|c|}{ Decompensated heart failure } & 3 \\
\hline & \multicolumn{2}{|c|}{ Vasovagal syncope } & 3 \\
\hline & \multicolumn{2}{|l|}{ Arrhythmia } & 5 \\
\hline & \multicolumn{2}{|l|}{ Anemia } & 3 \\
\hline \multirow{5}{*}{ Imbalance $(n=27)$} & \multicolumn{2}{|c|}{ Diseases of the spinal cord } & 13 \\
\hline & \multicolumn{2}{|c|}{ Polyneuropathy } & 11 \\
\hline & \multicolumn{2}{|c|}{ Normal-pressure hydrocephalus } & 3 \\
\hline & \multicolumn{2}{|c|}{ Parkinson's disease } & 3 \\
\hline & \multicolumn{2}{|c|}{ B12 deficiency } & 2 \\
\hline $\begin{array}{l}\text { Nonspecific and } \\
\text { multifactorial causes } \\
(n=7)\end{array}$ & \multicolumn{2}{|c|}{$\begin{array}{l}\text { Presyncope and more than one reason among those } \\
\text { under imbalance title were reported in } 4 \text { cases, and in } \\
3 \text { cases, multiple causes and nonspecific phobic } \\
\text { symptoms were reported. }\end{array}$} & 7 \\
\hline
\end{tabular}

ECG was found to be abnormal in 8 patients with vertigo $(15.1 \%), 6$ patients with presyncope $(28.6 \%)$, and two patients with imbalance. Eight $(8 \%)$ patients had chronic atrial fibrillation, $3(3 \%)$ had ventricular extrasystole, $3(3 \%)$ had paroxysmal atrial fibrillation, and 2 had an atrioventricular block. Arrhythmia was more common in the presyncope group $(\mathrm{n}=4,19 \%)$, and chronic atrial fibrillation was more common in the vertigo group $(n=5,9.5 \%)$.

ECHO; was found abnormal in 36 patients with vertigo $(67.9 \%)$. Ejection fraction (EF) was $40-50 \%$ in 8 of these patients (15\%), EF $>50 \%$ in 28 of these patients $(52.8 \%)$, and wall motion abnormality was detected in five patients. Abnormal findings were found in ECHO in 16 patients with presyncope (76.2\%); distinct EF pathology was detected in 4 patients, in two patients (9.5\%), EF was 40$50 \%$, and in two patients $(9.5 \%)$, EF was $>40 \%$. In the imbalance group, 17 patients (63\%) had pathological findings in ECHO, but the EF value was found to be $>50 \%$ in all patients.

On audiometric examination, 73 patients had different levels of bilateral presbycusis. It was determined that 5 patients used hearing aids. 6 patients were recommended hearing aids, though it was learned that they could not adapt. There are 53 patients in the vertigo group (51\%), 21 in presyncope $(20.2 \%), 27$ in 
imbalance (26\%), and 3 in nonspecific sensation of dizziness (2.8\%). Multiple causes of dizziness were identified in 4 cases. Patient diagnoses are shown in Table IV.

\section{DISCUSSION}

Visual, proprioceptive, and vestibular signals carry information about the position of the head and body in space. Damage to one or more of these systems results in dizziness complaints. Its prevalence is $11-32.5 \%$ (3). Prevalence increases with age (4). Approximately $3 \%$ of emergency department admissions are due to an imbalance in the general population (5). The applications for primary health care facilities were reported as $6.78 \%$ in those aged between $65-74$ and $10.8 \%$ in those aged 85 and over (3). Gasmman and Rupprecht found the prevalence of dizziness to be $29.2 \%$ in 620 patients over 65 years of age (2). This means that one of three older adults presents with this complaint. After the evaluation of 100 patients who presented to the outpatient clinic due to balance disorder; the cases were grouped into 4 basic diagnosis groups as vertigo, presyncope, imbalance, and nonspecific sensation of dizziness. Multiple causes of dizziness were identified in 4 cases.

It is essential to recognize that older dizzy patients typically present with a different symptom profile than their younger counterparts (6). Younger patients more often complain of true vertigo, nausea, and emesis, whereas older patients more often report symptoms of unsteadiness, imbalance, and disequilibrium. The main complaint in our patients is balance disorder. However, they depicted the balance disorder with different definitions when they applied. Fear of falling/being about to fall (83\%), imbalance/inability to balance/swinging (76\%), sense of motion of the surroundings (43\%), dizziness/feeling like there was something inside the head (43\%), inability to stand up, standing (21\%) were the main reasons for the application. In a similar study, it was found that among 417 patients over 65 years of age admitted to the emergency department due to dizziness complaints, the most frequent reason for the application was being unable to stand up (69\%), which was followed by an imbalance $(67 \%)$, a sensation of motion of surroundings $(55 \%)$, a tendency to fall $(54 \%)$, and dizziness (42\%) (7).

The patients included in the study defined the act of standing up (91\%) as the most common triggering factor. Other common triggers were getting up from bed (52\%), sudden change of body and head position $(38 \%, 36 \%)$. Hurvitz and Tinetti reported that dizziness complaint was triggered especially during standing up and with head movements (3) while Gassmann and Rupprecht reported that it was triggered by standing up and walking (2). Standing up was identified as the common trigger in both groups.

The most common accompanying symptoms were tinnitus (45\%), hearing loss (42\%), falls (36\%), blackout (33\%), nausea, and vomiting $(32 \%)$. Given the age distribution of the study group, it is impossible to conclude that tinnitus and hearing loss are real accompaniments. Because $1 / 3$ hearing loss is defined in those between $65-74$ years and $1 / 2$ in 75 and over (8). In the audiological examinations, sensorineural hearing loss was detected in 73 patients at different levels. 5 cases used hearing aids. 6 patients were recommended hearing aids but could not use them. This age group receives multiple medical treatments. Management of cerebrovascular and cardiovascular causes of dizziness usually involves controlling the underlying risk factors. Appropriately titrating antihypertensive medication is particularly critical to avoid orthostatic hypotension or adverse drug effects resulting in dizziness (9). When the occurrence and course of the complaint were evaluated, all of the patients emphasized that the onset of symptoms was sudden $(100 \%)$. Entirety or a period of the disease was in attacks in ninety-four (94\%) patients, while 6 patients $(6 \%)$ defined 
persistent complaints. Five of the patients whose complaints were continuous were evaluated for central causes and one for multiple causes. This result was found to be consistent with our practice and general knowledge. In the pathologies of the proprioceptive system, there is an increase in the imbalance in darkness due to the disappearance of the stimuli from the visual system. In our patient group, it was found that complaints increased in darkness in this group.

The gold standard for diagnosis is the correct coupling of detailed history and examination (10). Postural disorder was detected in 17 patients, nystagmus in the direction of rapid phase view in 18 patients, nystagmus during positional testing in 25 patients, non-reversible nystagmus in 3 patients, and non-nystagmus cerebellar system involvement in 11 patients were determined, and further investigation was planned.

In these cases, it is impossible to clarify the diagnosis without positional testing. For this purpose, routine Dix-Hallpike was performed in all cases without contraindications, and the cases were evaluated with Roll test if deemed necessary. BPPV is the most common cause of vertigo (11). It is seen in $20-30 \%$ of patients with dizziness complaints (12). The positional test was positive in $25(25 \%)$ patients in our study. No significant neurological and neurotological data were found in the cases evaluated under the presyncope title.

All patients aged 65 years or older suspected by a physician should undergo further examination. The association of isolated vertigo and dizziness with acute stroke was $11 \%$. It is more common, especially in PICA involvement (13). Therefore, MRI should be preferred if it can be performed outside of emergencies (14). Cerebral and posterior fossa MRI scans were planned in all cases, and specific or non-specific findings were detected in 86 cases. Acute stroke was detected in 15 patients diagnosed with vertigo (14\%), and a vestibular schwannoma image was obtained in one patient. Acute stroke cases were of $73 \%$ posterior, $27 \%$ anterior circulation origin and were evaluated as a minor stroke. In 12 of 13 patients who underwent spinal MRI due to their history characteristics, imaging revealed pathological findings and cervical spondylosis in $3(23 \%)$ patients. This finding was not considered a surprise for the current age group. In the etiology of dizziness, vestibular diseases are seen as the most common cause (15-17). Based on well documented data, in the general population, vertigo was found to be $45-54 \%$, imbalance> $16 \%$, presyncope $>14 \%$ and nonspecific dizziness as approximately $10 \%$ in outpatients (17). The most common reason in emergency department admissions was presyncobal dizziness developing based on cardiovascular disease (18). Presyncope connotes lightheadedness and the sense of an impending fainting episode. It is often associated with transient diffuse cerebral hypoperfusion (11). In our study, outpatients were included. In this group, the most common cause was determined as vestibular diseases. The function of semicircular canals and otoconia gradually decreases due to age-related demineralization. This may cause blood vessel and circulation abnormalities leading to obstruction of inner ear circulation. Vascular stress of the anterior vestibular artery may reduce blood flow to the labyrinth and cause serious damage to the macula and otoconia detachment (19). It was found to be consistent with outpatient results in the general population. $34(64.2 \%)$ of 53 patients in the vertigo subgroup were female. In this title, vestibular migraine and BPPV have led to the prediction that the female gender may be predominant. The male gender was statistically significantly higher than the females in the presyncope group. This increase can be attributed to the higher prevalence of cardiovascular diseases in men. The male gender is more in the imbalance group. No clear comment could be made on this subject. The most detrimental consequences of imbalance are the patient's social and functional loss. Older individuals who suffer 
from dizziness are at a significantly higher risk of accidental falls and consequent injuries (11). In addition, systemic and metabolic diseases, decreased muscle mass, side effects of drugs may increase imbalance. Falling is an inevitable result. In all neurological diseases, the rate of falling at least once a year is $34 \%$ (20). This rate was found to be $45 \%$ in neurology outpatient clinics in our country (21). In our study, 36 (36\%) of our patients defined falls. Stevens found that the fall in older patients with dizziness complaints was 2.11 (1.69 - 2.64) times higher (22). Another study found that those who suffered from dizziness in their history in the last six months experienced a fall time more than those who did not (23). There was no significant difference between the diagnostic groups of patients with fall complaints.

\section{Limitations}

This study had some limitations. The numbers of the groups in which the patients were separated were very different from each other. This situation hindered the statistical comparison of the groups with each other. This situation can be prevented with a larger number of patients.

\section{CONCLUSION}

Dizziness is one of the most common reasons for hospital admission and negatively impacts the quality of life, especially in the geriatric population. In this group of patients, it is essential to evaluate the detailed history, neurological and neurotological examination findings, and support imaging when necessary. Accurate diagnosis and related treatment increase the patients' quality of life while providing early recognition of central nervous system diseases. Our study is the first etiologic study in this area in the geriatric population.

\section{Conflict of Interest and Funding}

The authors declare no conflict of interest.

The study was not funded.

\section{Ethics Committee Approval}

The study protocol was approved by the ethics committee of Cukurova University, Turkey, with a decision date - number 27 - 3.1.2014.

\section{Author Contributions}

Author DO performed manuscript writing, data collection, data interpretation; Author MB contributed to data acquisition and interpretation; Author SB contributed to data interpretation, performed analysis, and manuscript writing. All authors have approved the final article.

\section{REFERENCES}

1. Ciorba A, Bianchini C, Scanelli G. The impact of dizziness on quality-of-life in the elderly. Eur. Arch. Otorhinolaryngol. 2017; 274: 1245-1250.

2. Gassmann KG, Rupprecht R. Dizziness in an older community dwelling population: a multifactorial syndrome. J. Nutr. Health Aging 2009; 13(3): 278-82.

3. Tinetti ME, Williams CS, Gill TM. Dizziness among older adults: a possible geriatric syndrome. Ann. Intern. Med. 2000; 132(5): 337-44.

4. Fernández L, Breinbauer HA, Delano PH. Vertigo and dizziness in the elderly. Front. Neurol. 2015; 6: 144.

5. Neuhauser HK. Epidemiology of vertigo. Curr. Opin. Neurol. 2007; 20(1): 40-6.

6. Piker EG, Jacobson GP. Self-report symptoms differ between younger and older dizzy patients, Otol. Neurotol. 2014; 35: 873-879.

7. Maarsingh OR, Dros J. Causes of persistent dizziness in elderly patients in primary care. Ann. Fam. Med. 2010; 8: 196-205.

8. Uzun C. Audiological findings in patients with vertigo. Trakya University Faculty of Medicine. Dissertation. Edirne 1995; 2-42.

9. Pont L, Alhawassi T. Challenges in the management of hypertension in older populations. Adv. Exp. Med. Biol. 2017; 956: 167-180.

10. Saccomano SJ. Dizziness, vertigo, and presyncope:what's the difference? Nurse Pract. 2012; 37(12): 46-52.

11. Alyono JC. Vertigo and dizziness. Otolaryngol. Clin. north Am. 2018; 51(4): 725-740.

12. Walther LE, Rogowski M, Schaaf H, et al. Falls and dizziness in the elderly. Otolaryngol. Pol. 2010; 64 (6): 354-357.

13. Kroenke K, Lucas CA, Rosenberg ML. Causes of persistent dizziness. A prospective study of 100 patients in ambulatory care. Ann. Intern. Med. 1992; 117(11): 898904.

14. Kuroda R, Nakada T, Ojima T, et al. The triAGe+ score for vertigo or dizziness: a diagnostic model for stroke in the emergency department. J. stroke Cerebrovasc. Dis. 2017; 26(5): 1144-1153.

15. Lee H. Isolated vascular vertigo. J. Stroke. 2014; 16: 124 130. 
16. Rubin DI, Cheshire WP. Evaluation of "dizziness" in the neurology office. Semin Neurol. 2011; 31: 029-41.

17. Post RE, Dickerson LM. Dizziness: a diagnostic approach. Am. Fam. Physician 2010; 82(4): 361-8.

18. Kerber KA, Brown DL, Lisabeth LD, et al. Stroke among patients with dizziness, vertigo, and imbalance in the emergency department: A population-based study. Stroke 2006; 37(10): 2484-2487.

19. Babac S, Djeric D, Petrovic-Lazic M, et al. Why do treatment failure and recurrences of benign paroxysmal positional vertigo occur? Otol. Neurotol. 2014; 35: 110510

20. Larson LM, Sliter R, Helmer SD. Outcomes in elderly fall victims: what happens after hospital discharge? Am. J. Surg. 2016; 212: 1106-1114.
21. Soyuer F, Unalan D, Erdogan F. Falling prevalence and risk factors in patients admitted to the Department of Neurology, Faculty of Medicine, Erciyes University. Turkish Journal of Neurology 2006; 12(4): 269.

22. Stevens KN, Lang IA, Guralnik JM, et al. Epidemiology of balance and dizziness in a national population: findings from the english longitudinal study of ageing. Age ageing 2008; 37(3): 300-5

23. Aratani MC, Perracini MR, Caovilla HH, et al. Disability rank in vestibular older adults. Geriatr. Gerontol. Int. 2011; 11(1): 50-4. 